Purdue University Purdue e-Pubs

$1-1-2010$

\title{
Some Evidence on the Nature and Growth of Input Trade
}

David Hummels

Purdue University

Laura Puzzello

Purdue University

Follow this and additional works at: http://docs.lib.purdue.edu/ciberwp

Hummels, David and Puzzello, Laura, "Some Evidence on the Nature and Growth of Input Trade" (2010). Purdue CIBER Working Papers. Paper 62.

http://docs.lib.purdue.edu/ciberwp/62

This document has been made available through Purdue e-Pubs, a service of the Purdue University Libraries. Please contact epubs@purdue.edu for additional information. 
Center for International

Businesses Educaronand Research

\title{
Some Evidence on the Nature and Growth of Input Trade
}

David Hummels

Purdue University

Laura Puzzello

Purdue University

CIBER Working Paper Series

2010-001 


\section{Introduction}

Why do countries trade intermediate inputs? Recent studies have documented that trade in intermediate inputs is a large and growing fraction of overall trade ${ }^{1}$. With this documentation has come an increasing interest in explaining why this trade takes place and whether it is in important ways different from trade in final goods. For example, input trade may be driven by factor endowment differences (as in Arndt, 1997, 1998; Deardorff, 2001a, 2001b), by the balance of scale economies vs. trade costs (as in Krugman and Venables, 1995,1996; Venables, 1996), by multinational firms seeking to trade specialized inputs on an intra-firm basis (as in Helpman, 1984; Zhang and Markusen, 1999; Venables, 1999). Many of these motivations and explanations simply borrow theoretical determinants from the larger literature on trade in final consumer goods.

We extend a standard model of international trade with intermediate inputs. This model, originally due to Krugman and Venables (1995, 1996), is widely used in literatures on international trade and agglomeration economies. It assumes a strong form of symmetry between intermediate and final goods: the sensitivity of a good's demand to relative prices and trade costs is assumed to be independent of its "end-use". We derive an implication that, for a given industry, the input share of bilateral trade depends exclusively on the industrial absorption share of intermediates from that industry. That is, the intermediate input share of bilateral trade in an industry should not be explained by factor and trade costs once its industrial absorption share is controlled for. An empirical failure of the theory would instead imply that the effect of factor costs and trade barriers is not symmetric across final and intermediate international flows.

We empirically test this prediction using a unique dataset, the Asian International Input-Output Tables. These tables allow us to examine country and industry level determinants of the sourcing of intermediate goods and the extent of vertical specialization.

\footnotetext{
${ }^{1}$ Borga and Zeile, 2004; Campa and Goldberg, 1997; Feenstra, 1998; Feenstra and Hanson, 1999; Hanson et al., 2001, 2005; Hummels et al., 1998, 2001; Yeats, 2001.
} 
This is not the first paper to look at input trade and its determinants; however, existing papers have two important flaws: they require definitions of intermediate vs. final goods that are problematic, and they lack information on where the input is used. In a typical approach researchers examine the definition of particular product codes with the SITC or HS nomenclatures and then determine whether the code in question is an intermediate or final good. Examples include the UN's BEC or "Broad Economic Category" classification, and the US "end use" classifications. Several authors have also identified intermediates as those goods whose product code definitions include the words "parts" or "components". Of course, any such division is arbitrary -- including goods that are not intermediates and excluding goods that are intermediates. For example, many chemical compounds are inputs into production, in some sense "parts", but are categorized by their appropriate molecular name.

Similarly, the same product can be both an input and a final good. Many food products such as wheat flour are both inputs (for restaurants and food processing firms) and final consumer goods. Automobile tires are purchased both by firms as an input into car production, and by final consumers installing tires on their cars. In both examples, tires and wheat flour are used in similar manners by firms and consumers, the primary differences being who is doing the assembly, whether the "assembled" good is now tradeable, and whether the assembler can change locations in response to cost pressures. For example, the firm that uses tires or wheat flour can assemble them into a trade-able good, and that firm is itself internationally mobile, potentially relocating production to be close to input supplies. In contrast, the assembly by the household is for use by the household not for trade, and the household is not internationally mobile.

This point suggests that when explaining the sourcing of intermediates and the extent of vertical specialization one would also like to know where inputs are used. One country may import ball bearing while another imports machine tools -- this may reflect differences in their comparative advantage in ball bearing vs. machine tools, or it may simply reflect differences in which industries use these inputs. This suggests a second problem with using an "intermediates" definition with simple trade data -- machine tools and ball bearings are likely employed in many different industries. Even if one can convincingly define a good as an intermediate trade flow data this does not indicate in 
which sector that intermediate is used. Without this information one is unable to explore the role played by the "using" industry, and whether the "using" industry is itself mobile in response to the availability of parts and components.

A consequence of this definitional problem is that many papers that separate "intermediates" and "final goods" in regressions find similar correlates in each case. That is, these goods do not appear to look statistically different. This may be because intermediate and final goods are, in fact, similar. Or it may be due to wholesale misclassification.

By using the Asian IO table data we solve both problems. First, intermediate inputs are defined by their use rather than by product code definition. Second, we can observe the share of each industry's output that is absorbed by other industries and by final consumers. In these respects our approach is similar to that employed by Hummels, Ishii, and Yi (2001) who use OECD input-output tables for related purposes. An important difference is that we are able to observe from where, internationally, particular goods are sourced. This enables us to examine a richer set of determinants related to exporter characteristics.

Our approach is also related to a distinct literature that examines the determinants of intrafirm sales, which are sales of intermediate inputs between affiliates of the same multinational firm. This literature has three problems. One, intrafirm sales data are quite limited in time series and geographic coverage. Two, to the extent that intermediate inputs are also traded on an arms length basis, intrafirm sales miss this trade. Three, multinational firms may span multiple industries, making it difficult to draw inferences about the role of the "using" industry.

\section{Data Description}

Our empirical analysis uses the Asian International Input-Output (AIO, henceforth) tables for the reference years of 1975, 1985, 1990, 1995 and 2000. These tables contain information on ten national Input-Output tables: China, Indonesia, Japan, 
Korea, Malaysia, the Philippines, Singapore, Taiwan, Thailand and the United States ${ }^{2}$. Bilateral details are retrieved exploiting trade data.

The special feature of the AIO tables is that transactions in intermediates and final goods are distinguished on the basis of country-specific surveys. The distribution by source country of imported intermediates employs a proportionality assumption according to which a country imports intermediates of a particular good from a given source country in proportion to the share of bilateral imports in the destination country's total imports of that good. Accordingly, the amount of intermediate good $g$ used for production of good $h$, where $g$ is produced by country $j$ and $h$ by country $i, M_{j i}(g, h)$, is imputed as follows: $M_{j i}(g, h)=\frac{\text { Tot. } \operatorname{Imports}_{i j}(g)}{\text { Tot. } \operatorname{Imports}_{i}(g)} * M_{i}^{-i}(g, h)$, where $M_{i}^{-i}(g, h)$ is the amount of imported intermediate good $g$ used to produce country $i$ 's good $h$. Importantly, these imputations are adjusted when possible for additional information on the source country of imported intermediate, and suggestions from local specialists. For additional information on the methodology of compiling AIO tables, see Inomata (1997), Oyamada et al. (2005) and IDE (2008).

Those tables are available for 56 sectors in the year 1975, 38 sectors in 1985, 78 sectors in 1990 and 1995, and 76 sectors in 2000. Our analysis uses an aggregation of the AIO tables to 30 sectors $^{3}$ to make data comparable over time.

In Table 1 we report statistics on the importance of input trade for each country and each year. Panel A reports IT/GO -- imported inputs as a share of gross output in trade-able sectors of the economy. In larger economies (the US, Japan, China, Indonesia) the IT/GO ratio is quite small. This may reflect the greater availability and diversity of domestically produced inputs. For the remaining economies, imported inputs represent a significant fraction of gross output -- as high as one quarter for Malaysia and Singapore. The final column of panel A shows that imported inputs as a fraction of gross output are growing very rapidly in all countries except Korea.

Table 1 Panel B reports IT/TT -- imported inputs as a share in total trade (imports). This is the statistic that we will focus on primarily in our empirical analysis of

\footnotetext{
${ }^{2}$ For the year 1975 table, China and Taiwan are not included.

${ }^{3}$ The aggregation produces three primary sectors, twenty-one secondary sectors and six service sectors.
} 
the determinants of input trade. Again, most of the larger and more developed economies import fewer inputs as a share of total trade, though the differences are less pronounced than was seen in Panel A. In terms of growth rates, China, Malaysia, Philippines and Thailand are the large positive outliers while Korea saw little growth and input trade as a share of total trade significantly shrank for Japan, Taiwan, and the US. There are three possibilities behind the shrinking share of input trade. One, these last three countries are shifting away from assembly operations and so purchase fewer inputs than they did previously. Two, they still purchase foreign inputs but are shifting away supply sources covered by the Asian IO tables (e.g. US sourcing from NAFTA countries would not be counted). Three, non-input imports are simply growing much faster than input imports in these countries. Of these explanations the last seems the most likely given the evidence in Panel A showing that imported inputs as a share of gross output are small but growing for all three countries.

Finally, input trade is a two-way street. In Panel $\mathrm{C}$ we reverse the perspective and examine the importance of exported inputs as a share of total exports for each country. Here we see growth in exported inputs for Japan, Korea, Taiwan and Singapore, but shrinkage for the remaining countries. The patterns revealed in Panels B and C for Japan are especially interesting. They indicate a shift away from assembly and a shift toward provision of inputs for assembly elsewhere.

\section{Model}

In this section we extend a standard model of international trade with intermediate inputs. This model is originally due to Krugman and Venables (1995, 1996), and is also used in Hillberry and Hummels (2002) and Redding and Venables (2004). It assumes a strong form of symmetry between intermediate and final goods: the sensitivity of a good's demand to relative prices and trade costs is assumed to be independent of its "enduse". We derive an implication that, for a given industry, the input share of bilateral trade depends exclusively on the industrial absorption share of intermediates from that industry. That is, the intermediate input share of bilateral trade in an industry should not be explained by factor and trade costs once its industrial absorption share is controlled for. 
We follow the model derivation and extension in Hillberry-Hummels (2002). In this model goods are both final goods and intermediate inputs. Demands in the first case are given by consumers and in the second case by using industries. In the case of a onesector economy, total expenditures for a good depend on consumer income and on the extent of industry in a location. In a more general model with $H$ industries, expenditures for industry $h$ in a location depend on consumer income and on the distribution of industry in that location. For example, if $h$ is auto parts, expenditures on auto parts rise if a location primarily produces automobiles and falls if a location primarily produces agriculture.

Consider a world with $i=1, \ldots, R$ countries. Consumers have identical CobbDouglas preferences across commodities $h=1, \ldots, H$ and Dixit-Stiglitz preferences over differentiated varieties:

$U_{i}=\prod_{h} C_{i, h}^{\eta_{h}}$ with $C_{i, h}=\left(\sum_{m_{h}}\left(c_{i, m_{h}}^{h}\right)^{\frac{\sigma-1}{\sigma}}\right)^{\frac{\sigma}{\sigma-1}}$

where $\eta_{h}$ is the consumers' expenditure share in varieties of sector $h$, and $\sigma$ is the elasticity of substitution betweens pairs of differentiated varieties. Let $\sigma$ be the same for all sectors $h$.

Firms use two primary factors, capital $(K)$ and labor $(L)$, and intermediates for the production of a given variety. Both factors are perfectly mobile within a country but immobile across countries. Each variety/good is used for consumption and production. In order to produce a variety of good $h$ firms in country $i$ use fixed and marginal quantities of a composite input $Z$ which consists of labor, capital and intermediates:

$Z_{i}^{h}=K_{i}^{h \mu_{k}^{h}} L_{i}^{h} \mu_{L}^{h} \prod_{g} M_{i}^{g h} \mu_{g}^{h}$ with $\mu_{k}^{h}+\mu_{L}^{h}+\sum_{g} \mu_{g}^{h}=1$

where $\mu_{k}^{h}, \mu_{L}^{h}$ and $\mu_{g}^{h}$ are respectively the cost shares of capital, labor and intermediate input $g$ in the production of good $h . M_{i}^{g h}$ is the bundle of intermediates from sector $g$ used in the production of good $h$.

$$
M_{i}^{g h}=\left(\sum_{n_{g}}\left(m_{n_{g}}^{g h}\right)^{\frac{\sigma-1}{\sigma}}\right)^{\frac{\sigma}{\sigma-1}}
$$


where $m_{n_{g}}^{g h}$ is the quantity of a firm's output from sector $g$ used in sector $h$. We assume the elasticity of substitution between varieties of intermediates is the same across sectors and equal to the elasticity of substitution in demand ${ }^{4}$.

Given the description of technology in (2), industry $h$ spends a proportion $\mu_{g}^{h}$ of total costs/revenues in intermediates from sector $g$ :

$$
\bar{P}_{i}^{g} M_{i}^{g h}=\mu_{g}^{h} X_{i}^{h}
$$

where $\bar{P}_{i}^{g}$ is the price index characterizing sector $g$, and $X_{i}^{h}$ is the gross output of industry $h$. The shares $\mu_{g}^{h}$ correspond to the standard use coefficients in an input-output table.

We have assumed that utility is CES over distinct varieties of good $g$. This implies that final consumer demand for each variety of good $g$ originating in exporter $j$ can be written

$$
c_{j i}^{g}=\frac{\left(p_{j}^{g} \tau_{i j}\right)^{-\sigma}}{\bar{P}_{i}^{g}{ }^{1-\sigma}} * \eta^{g} Y_{i}
$$

Industrial demands arising from sector $h$ for good $g$ are the same, except that we replace the share of consumer income spent on $\operatorname{good} g, \eta^{g} Y_{i}$, with the input-output coefficient $\mu_{g}^{h}$ multiplied by output of sector $h$,

$m_{j i}^{g h}=\frac{\left(p_{j}^{g} \tau_{i j}\right)^{-\sigma}}{\bar{P}_{i}^{g}{ }^{1-\sigma}} * \mu_{g}^{h} X_{i}^{h}$

Summing over all using industries we arrive at country $i$ 's total industrial use for good $g$ sold by exporter $j$

$$
m_{j i}^{g}=\sum_{h} m_{j i}^{g h}=\frac{\left(p_{j}^{g} \tau_{i j}\right)^{-\sigma}}{\bar{P}_{i}^{g}{ }^{1-\sigma}} * \sum_{h} \mu_{g}^{h} X_{i}^{h}
$$

Adding together final consumer and industrial demands for a variety of good $g$ produced in country $j$ we have

\footnotetext{
${ }^{4}$ The implication we focus on in this paper holds as long as the elasticity of substitution between varieties of a given good is independent of its "end-use".
} 
$q_{j i}^{g}=c_{j i}^{g}+m_{j i}^{g}=\frac{\left(p_{j}^{g} \tau_{i j}\right)^{-\sigma}}{\bar{P}_{i}^{g}{ }^{1-\sigma}} * E_{i}^{g}$

where total expenditure on good $g$ by importer $i$ is $\quad E_{i}^{g}=\eta^{g} Y_{i}+\sum_{h} \mu_{g}^{h} X_{i}^{h}$

Expressions (7) and (8) give us the quantity consumed for a single variety. To translate that into total expenditures, we multiply by the number of distinct varieties produced by exporter $j, N_{j}^{g}$, and the price per variety, to yield

$$
T_{j i}^{g}=N_{j}^{g} p_{j}^{g} q_{j i}^{g}=N_{j}^{g} \frac{\left(p_{j}^{g}\right)^{1-\sigma} \tau_{i j}^{-\sigma}}{\bar{P}_{i}^{g}{ }^{1-\sigma}} * E_{i}^{g}
$$

Industrial expenditures on good $g$ produced by exporter $j$ arising from using sector $h$ in country $i$ is then

$$
M_{j i}^{g h}=N_{j}^{g} p_{j}^{g} m_{j i}^{g h}=N_{j}^{g} \frac{\left(p_{j}^{g}\right)^{1-\sigma} \tau_{i j}^{-\sigma}}{\bar{P}_{i}^{g}}{ }^{1-\sigma} \mu_{g}^{h} X_{i}^{h}
$$

Equations (10) and (9) are complicated expressions involving many hard to measure variables. But note that by taking a ratio of the two we eliminate all these variables except for the expenditures shares

$$
\frac{M_{j i}^{g h}}{T_{j i}^{g}}=\frac{\mu_{g}^{h} X_{i}^{h}}{E_{i}^{g}}
$$

We also find it useful to construct total expenditures on input $g$ from country $j$ by summing over all using sectors $h$. That yields

$$
M_{j i}^{g}=N_{j}^{g} p_{j}^{g} m_{j i}^{g}=N_{j}^{g} \frac{\left(p_{j}^{g}\right)^{1-\sigma} \tau_{i j}^{-\sigma}}{\bar{P}_{i}^{g}{ }^{1-\sigma}} * \sum_{h} \mu_{g}^{h} X_{i}^{h}
$$

Taking the ratio of (12) and (9) we have input trade as a share of total trade:

$$
\frac{M_{j i}^{g}}{T_{j i}^{g}}=\frac{\sum_{h} \mu_{g}^{h} X_{i}^{h}}{E_{i}^{g}}
$$

This is the key prediction of the model. Input trade as a share of total trade depends exclusively on the industrial absorption share for industry $g$ 's products. This is 
completely independent of exporter characteristics. That is, exporter characteristics such as size (operating through $N_{j}^{g}$ ), product prices, and trade costs affect the level of input trade and the level of final consumer trade. But because exporter characteristics affect both in precisely the same way the characteristics cancel out in equation (13). It is not generally possible to test this conjecture as other data sets lack information either on the sourcing of inputs and or on the end-use destination of those inputs. However, since the Asian IO tables contain both pieces of information we can construct the elements in equations (11) and (13), and formally examine both hypotheses.

\section{Empirics}

As a starting point we use AIO tables data to estimate fairly standard gravity style regressions motivated by equations (9) and (10). We first relate sales of inputs $g$ from exporter $j$ to importer $i$ to be used in industry $h$ to the determinants of trade suggested by equation (10).

$$
\begin{aligned}
\log M_{j i}^{g h} & =\alpha+\beta_{1} \log \mu_{g}^{h} X_{i}^{h}+\beta_{2} \log \left[\left|\left(\frac{K}{L}\right)_{i}-\left(\frac{K}{L}\right)_{j}\right|\right]+\beta_{3} \log 1+\operatorname{tar}_{j i}^{g} \\
& +\beta_{4} \log \left(D I S T_{i j}\right)+\beta_{5} \text { Contig }_{j i}+\beta_{6} \operatorname{Lang}_{j i}+\beta_{7} \log G O_{j}^{g}+u_{j i}^{g h}
\end{aligned}
$$

where $\operatorname{tar}_{j i}^{g}$ as the tariff rate on country $i$ 's imports of good $g$ produced by country $j$, $\left(\frac{K}{L}\right)_{i}-\left(\frac{K}{L}\right)_{j}$ is the difference in trade partners' relative factor endowments, DIST is the geographical distance in kms between trading partners; Contig and Lang are dummy variables which take on one if the trading partners share a border or speak a common primary language ${ }^{5}$, respectively, and $G O_{j}^{g}$ is gross output of good $g$ in exporter $j$. We then estimate the same equation, but using total trade as the dependent variable and replacing industrial absorption with total absorption.

\footnotetext{
${ }^{5}$ Data for geographical factors are taken from the CEPII dataset.
} 


$$
\begin{aligned}
\log T_{j i}^{g} & =\alpha+\beta_{1} \log E_{i}^{g}+\beta_{2} \log \left[\left|\left(\frac{K}{L}\right)_{i}-\left(\frac{K}{L}\right)_{j}\right|\right]+\beta_{3} \log 1+\operatorname{tar}_{j i}^{g} \\
& +\beta_{4} \log \left(D I S T_{i j}\right)+\beta_{5} \text { Contig }_{j i}+\beta_{6} \text { Lang }_{j i}+\beta_{7} \log G O_{j}^{g}+u_{j i}^{g h}
\end{aligned}
$$

Results are reported in the first two columns of Table $2^{6}$. The gross output and expenditure variables are highly significant in both regressions as are the trade cost measures distance, contiguity, and common language. Differences in factor endowments are highly significant for total trade (countries trade with partners with different endowments) but not for input trade.

The next step is to examine whether input trade and total trade depend on different determinants, or on the same determinants to a different degree. We use the Asian IO table data to calculate the left and right hand side of equation (13) for each industry $g$ that exporter $j$ ships to importer $i$. In Figure 1 we display values for the US as importer, buying 30 goods $g$ from 9 different exporters, for 270 observations. We plot the intermediate input share of total US imports of $g$ from $j, \frac{M_{j, u s}^{g}}{T_{j, u s}^{g}}$, on the vertical axis and US expenditures on $g$ for industrial uses relative to total expenditures on $g$, $\frac{\sum_{h} \mu_{g}^{h} X_{u s}^{h}}{E_{u s}^{g}}$, on the horizontal axis. Note that there are only 30 distinct values for expenditures on the horizontal axis ${ }^{7}$. Were equation (13) to precisely and completely characterize trade, the intermediate input share of bilateral trade would be independent of the source country. Consequently, one unique observation should characterize each product $g$ and fall exactly on the 45 degree line.

Figure 1 shows how this prediction performs empirically looking at the U.S. separately for each year in the sample. In each year, for each sector's industrial absorption share we observe more than one value of the input share of bilateral trade, i.e., the intermediate inputs share of bilateral trade is not independent of the source country. Table 3 reports the correlation coefficients between the left and right hand sides of

\footnotetext{
${ }^{6}$ See note 10 for a description of the sample.

${ }^{7}$ The year 1975 is an exception as we have data on 29 distinct goods.
} 
equation (13) for each of the Asian IO country importers in each year. We find positive correlations between the left and right hand side of equation (13) for all countries and years, but these correlations are far from 1.

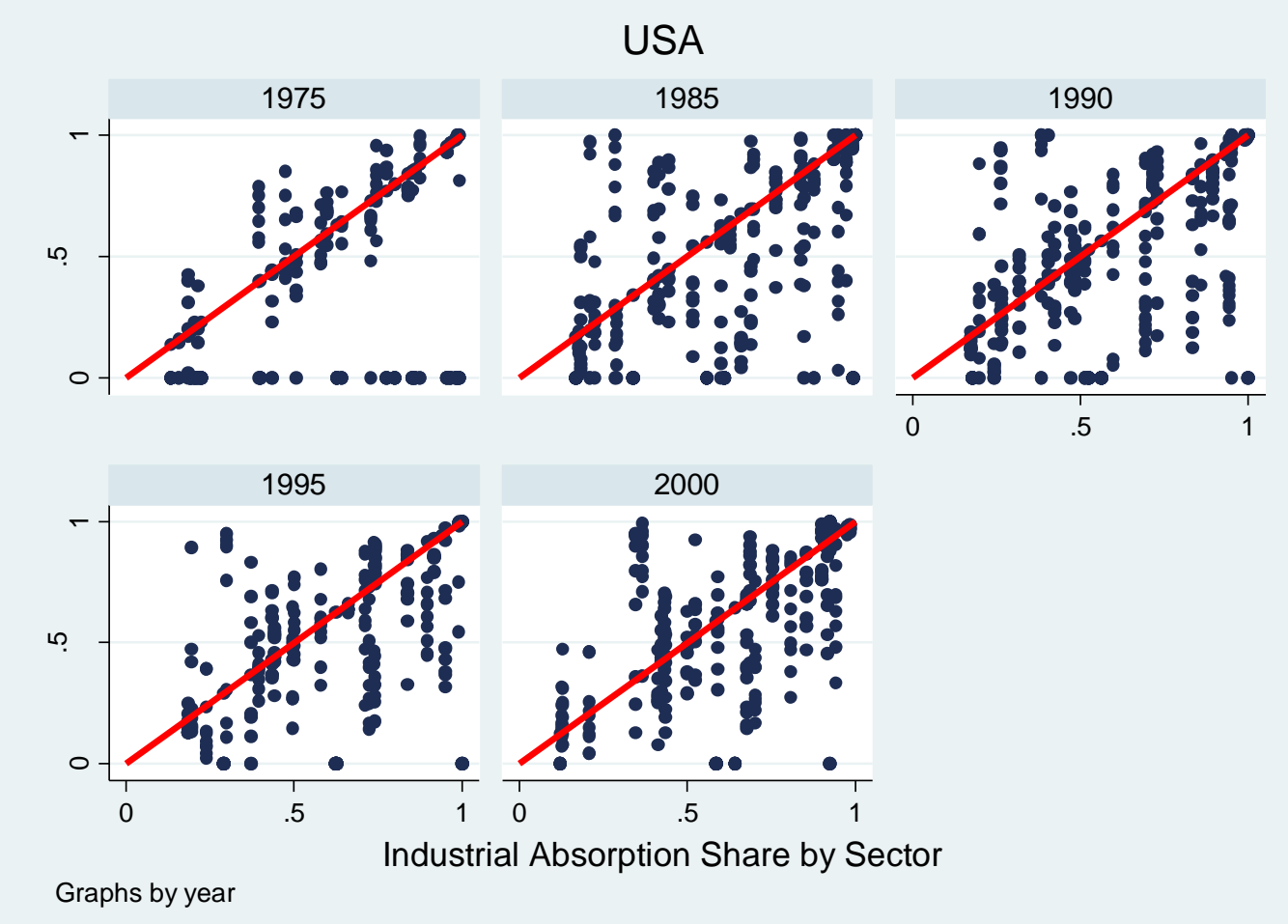

Figure 1 Trade Partner Independence of U.S. Intermediate Input Share of Bilateral Trade.

More formally, we examine whether the intermediate input share of trade at the industry level depends on expenditure data taken from the IO tables. Taking logs of equation (11) we estimate the following model:

$\log \left(\frac{M_{j i}^{g h}}{T_{j i}^{g}}\right)_{t}=\alpha+\beta \log \left(\frac{\mu_{g}^{h} X_{i}^{h}}{E_{i}^{g}}\right)_{t}+\varepsilon_{j i t}^{g h}$

where $\varepsilon_{j i t}^{g h}$ is a normally distributed random error. According to the theory, in each time period, the estimated coefficient for the constant should be zero and that of the slope equal to one. We pool over all $i-j-g-h$ variation, estimate separate samples for each year, and report results in Table 4.

Two things are notable in this table. First, the estimated coefficients are statistically different from the prediction of 1 but they are large and highly significant, 
and the simple model explains approximately 70 percent of the variation in the input to total trade ratio. ${ }^{8}$ Second, the intercepts are negative rather than the predicted zero. This suggests that input trade relative to total trade is much lower than the model predicts.

What causes deviations of input trade from the baseline prediction in equations (11) and (13)? One particular deviation of the data from the model can be seen by noting that many of the input trade shares in Figure 1 line up at zero. These are cases where an importer's industrial absorption share for a given good is positive while its input share of bilateral trade is zero. This turns out to be a common pattern. In Table 5 we display the frequency of unpredicted zeros, that is, cases where industrial input expenditures are positive but input trade from a particular source country is zero. The first row sums over all using industries $h$ for a given $i-j-g$ triplet, while the second row calculates the frequency for each $i-j-g-h$ case. When summing over all using industries, unpredicted zeros occur between 11 and 22 percent of the time. When considering each using industry separately the number rises substantially, to between 28 and 44 percent of cases. In both rows, the frequency of unpredicted zeros drops substantially over time.

What does this tell us? Simply that input demands are much more highly specialized than consumer demands. In the simple model above both consumers and producers have love of variety in their utility/cost functions which causes them to buy goods from all available sources. That is manifestly not the case with input trade -producers buy from a much narrower set of suppliers. That is precisely what one would expect if the inputs themselves were specifically adapted to particular end products.

We now examine whether, once expenditures are controlled for, the intermediate input shares depend on other arguments in equation (10), such as trade costs and the factor abundance (working through product prices). If so, we can reject the symmetry assumption used throughout the literature on intermediate input trade in favor of a hypothesis that this trade is fundamentally different.

The first specification we estimate adds bilateral trade cost controls to the baseline regression, as follows:

\footnotetext{
${ }^{8}$ These results are robust to the following changes: inclusion of year and/or source-destination sector fixed effects, and exclusion from the sample observations on the input shares of domestic intermediates.
} 
$\log \left(\frac{M_{j i}^{g h}}{T_{j i}^{g}}\right)=\alpha+\beta_{1} \log \left(\frac{\mu_{g}^{h} X_{i}^{h}}{E_{i}^{g}}\right)+\beta_{2} \log \left(\right.$ DIST $\left._{i j}\right)+\beta_{3}$ Contig $_{j i}+\beta_{4}$ Lang $_{j i}+\beta_{5} H O M E+\varepsilon_{j i t}^{g h}$

where $H O M E$ is an indicator variable that takes on one if the input share of bilateral trade is actually the input share of domestic intermediates in total consumption of domestic varieties. We estimate equation (17) separately for each year and report results in Table 6.

Several things are notable about the results. Expenditures shares are again large and positive and close to one. Bilateral distance has no effect on the input share of trade but the other trade cost measures do. Contiguous countries have a larger than predicted share of input trade, as do countries sharing a common language. But the largest effect is the HOME dummy. In all years except for 1975, the ratio of input to total trade is far greater for domestic than for foreign suppliers. Recall, if trade costs are symmetric for inputs and final goods their effect should wash out when we take the ratio in equation (11). This result then suggests that intermediate inputs are more sensitive to trade costs than final goods.

The only year for which results are surprising is 1975. Indeed, once expenditures are controlled for none of the bilateral-specific variables are significant. This does not appear to be due to country coverage, which is more sparse in 1975 (excluding China and Taiwan). Restricting country coverage in subsequent years to those observations that appear in the 1975 data, we find similar results.

Next, we eliminate domestic shipments from our sample and focus only on international trade. We also include variables intended to capture factor endowment differences. To explain, our model predicts that bilateral trade flows for a given variety depend on its price relative to the average domestic price for similar varieties. As prices depend on factor costs and the domestic price index for each good is mostly determined by domestic varieties, factors abundance differences affect the level of bilateral trade flows. However, under the null hypothesis in equation (11), the input share of bilateral trade is not responsive to factor abundance differences across trade partners.

We use two specifications. In the first we exploit the strong positive correlation between a country's per capita GDP and its capital-labor endowment to proxy factor abundances in each year to estimate: 


$$
\begin{aligned}
\log \left(\frac{M_{j i}^{g h}}{T_{j i}^{g}}\right)_{t} & \left.\alpha+\beta_{1} \log \left(\frac{\mu_{g}^{h} X_{i}^{h}}{E_{i}^{g}}\right)_{t}+\beta_{2} \log \left[\mid\left(\frac{g d p_{i}}{P_{o p_{i}}}\right)_{t}-\left(\frac{g d p_{j}}{P_{o p_{j}}}\right)\right]\right]+\beta_{3} \log D_{t} I S T_{j i}+ \\
& +\beta_{4} \text { Contig }_{j i}+\beta_{5} \text { Lang }_{j i}+\varepsilon_{j i t}^{g h}
\end{aligned}
$$

where the absolute difference in GDP per capita of trading partners proxies for their difference in relative factor endowments. The results in Table 7 show that per capita income differences do affect input shares of bilateral trade even after controlling for expenditures. In particular, an increase of $1 \%$ in the gap of countries GDP per capita decreases the input share of bilateral trade, on average and ceteris paribus by $0.07 \%{ }^{9}$. This effect is precisely estimated in each year with the exception of 1990. It then appears that factor costs differentials affects trade in intermediates and final goods asymmetrically.

Finally, we use explicit measures of capital/labor ratios along with tariffs for the year 2000 only $^{10}$ and estimate:

$$
\begin{aligned}
\log \left(\frac{M_{j i}^{g h}}{T_{j i}^{g}}\right)= & \alpha+\beta_{1} \log \left(\frac{\mu_{g}^{h} X_{i}^{h}}{E_{i}^{g}}\right)+\beta_{2} \log \left[\left|\left(\frac{K}{L}\right)_{i}-\left(\frac{K}{L}\right)_{j}\right|\right]+\beta_{3} \log 1+\operatorname{tar}_{j i}^{g} \\
& +\beta_{4} \log \left(D I S T_{i j}\right)+\beta_{5} \text { Contig }_{j i}+\beta_{6} \text { Lang }_{j i}+\beta_{7} \log G O_{j}^{g}+u_{j i}^{g h}
\end{aligned}
$$

The third column of table 2 reports our findings. Input shares of bilateral trade are lower the higher is the tariff imposed on the imported intermediate and the larger is the gap in countries relative factor endowments. Results are in line with our previous estimates.

\footnotetext{
${ }^{9}$ These results are robust to the inclusion of year and/or source-destination sector fixed effects.

${ }^{10}$ The sample coverage is slightly different from the one used in most of our empirical analysis as data on ad valorem tariff rates are taken from the GTAP database version 6, with reference year 2001. Establishing the concordance between the original AIO tables and the GTAP database allows us to focus on 34 sectors instead of 30 sectors. Data on countries factor endowments for the year 2000 are constructed as documented in Puzzello (2008).
} 


\section{IV.1 Growth Regressions}

An additional implication of the theoretical model outlined in section III is that the growth rate of intermediate input shares of bilateral trade equals the growth rate of industrial absorption shares. This becomes immediately apparent taking logs of equation (11) and the difference between two time periods:

$$
\log \left(\frac{M_{j i}^{g h}}{T_{j i}^{g}}\right)_{t}-\log \left(\frac{M_{j i}^{g h}}{T_{j i}^{g}}\right)_{t-1}=\log \left(\frac{\mu_{g}^{h} X_{i}^{h}}{E_{i}^{g}}\right)_{t}-\log \left(\frac{\mu_{g}^{h} X_{i}^{h}}{E_{i}^{g}}\right)_{t-1}
$$

We relate changes in the input share of trade to changes in the industrial absorption share, along with additional trade cost controls using the following specification:

$$
\begin{aligned}
\Delta \log \left(\frac{M_{j i}^{g h}}{T_{j i}^{g}}\right)_{t} & =\alpha+\beta_{1} \Delta \log \left(\frac{\mu_{g}^{h} X_{i}^{h}}{E_{i}^{g}}\right)_{t}+\beta_{2} \log \text { DIST }_{j i}+\beta_{3} \text { Contig }_{j i}+ \\
& +\beta_{4} \text { Lang }_{j i}+\beta_{5} \text { HOME }+v_{j i t}^{g h}
\end{aligned}
$$

We estimate changes between each of the 5 year data windows, as well as pooling all the changes into a single regression. The estimates in Table 8 provide three interesting insights. One, growth in the input share of trade is positively related to growth in the industrial share of expenditures. Two, between 1975-1990 the HOME dummy is large and significantly positive, but it becomes large and negative between 1995-2000. In other words, in the first 15 years of the sample, reliance on domestic sources for inputs relative to total trade grew substantially. However, in the last 5 year period, domestic sourcing fell dramatically. Similarly, the contiguity variable has little effect on the growth of inputs/total trade until the last period. Between 1995-2000, the sourcing of inputs/total trade from contiguous countries fell dramatically. Put together this suggests significant increases in the use of foreign inputs relative to domestic inputs and increases in the use of inputs sourced from far off foreign sources relative to nearby foreign sources. These patterns seem consistent with the growing importance of global production networks after the 80 's. 


\section{Conclusions}

In this paper we examine the determinants of input trade. We employ an extension of a widely used model of intermediate input trade in which inputs and final goods are considered symmetric up to differences in expenditure shares. This provides a null hypothesis that inputs and final goods are determined by the same factors.

Our estimates provide the following insights. One, the extent of industrial absorption relative to final consumption as measured by input-output tables does help explain the input share of trade. Two, contrary to the maintained assumption of symmetry from our null hypothesis, this is not the only determinant of input trade. Input trade is more likely to be characterized by zeros, less sensitive to factor endowment differences than final goods trade, and more sensitive to trade costs as measured by home bias, contiguity and common language. However, the role of home bias and contiguity is eliminated by the year 2000, consistent with the popular view of the internationalization of input trade.

\section{References}

Arndt S., "Globalization and Open Economy", North American Journal of Economics and Finance, 8(1), 71-79, 1997

Arndt S., "Super-Specialization and the Gains from Trade", Contemporary Policy Issues, Western Economic Association, 1998;

Borga M. and Zeile W., "Foreign Outsourcing and the Intrafirm Trade of U.S. Multinational Companies”, U.S. Bureau of Economic Analysis mimeograph, 2002

Campa J. and Goldberg L., "The evolving external Orientation of Manufacturing Industries: Evidence from Four Countries”, Federal Reserve Bank of New York Economic Policy Review, 79-99, 1997;

Deardorff A., "Fragmentation in Simple Trade Models", North American Journal of Economics and Finance, 12(2), 121-137, 2001a;

Deardorff, A., "Fragmentation across Cones", in S. Arndt and H. Kierzkowski (eds), Fragmentation, New Production Patterns in the World Economy, 2001b; 
Feenstra R. and Hanson G., "The Impact of Outsourcing and High-Technology Capital on Wages: Estimates for the United States, 1979-1990," Quarterly Journal of Economics, 114(3), 907-40, 1999;

Hanson G. H., Mataloni R. J. and Slaughter M. J., "Expansion Strategies of U.S. Multinational Firms", 245-294, in D. Rodrik and S. Collins (Eds.), Brookings Trade Forum, 2001;

Hanson G., Mataloni R. and Slaughter M., "Vertical Production Networks in Multinational Firms", Review of Economics and Statistics, 2005;

Hillberry R. and Hummels D., "Explaining home bias in consumption: the role of intermediate input trade", NBER W. P. 9020, 2002;

Hummels D., Ishii J. and Yi K., "The nature and growth of vertical specialization in world trade", Journal of International Economics, 54, 75-96, 2001;

Hummels, D., Rapoport, D., Yi, K.-M., "Vertical specialization and the changing nature of world trade"; Federal Reserve Bank of New York Economic Policy Review June, 79-99, 1998;

Inomata, S. (1997) "On the Adjustment of National I-O Framework for the Compilation of 1990 Asian Input-Output Table", in Report on Compilation Work for 1990 International Input-Output Table (IV), Asian International Input-Output Series, No. 54, Institute of Developing Economies, Tokyo.

Krugman P. and Venables A. J., "Globalization and the Inequality of Nations", Quarterly Journal of Economics, 110(4), 857-880, 1995;

Krugman P. and Venables A. J., "Integration, Specialization and Adjustment", European Economic Review, 40, 959-967, 1996;

Ng, F., \& Yeats, A., "Major trade trends in East Asia", World Bank Policy Research Working Paper 3084, 2003;

Oyamada, K., S. Arakawa, S. Inomata, H. Kuwamori, J. Nakamura, N. Okamoto, T. Sano and Y. Uchida (2005), "Data Estimation in Asian International Input-Output Table? Focusing on Indonesia, Malaysia, the Philippines, Singapore and Thailand", GTAP 6 Data Package Documentation, III.11.F, Center for Global Trade Analysis, Purdue University, 2005; 
Puzzello L., "A Symmetry Hypothesis and Measurement Biases in the Factor Content of Trade", mimeo, 2008;

Redding S. and Venables A., "Economic Geography and International Inequality", Journal of International Economics, 62, 53-82, 2004;

Venables A., "Equilibrium Location of Vertically Linked Industries", International Economic Review, 37 (2), 341-359, 1996;

Venables A., "Fragmentation and multinational production", European Economic Review, 43, 935-945, 1999;

Yeats, A., "Just How Big Is Global Production Sharing?" in Sven W. Arndt and Henryk Kierzkowski (Eds.), Fragmentation: New Production Patterns in the World Economy, 2001;

Zhang K. and Markusen J., "Vertical Multinational and Host-Country Characteristics", Journal of Development Economics, 59, 233-252, 1999; 
Table 1 Relative Importance of Inputs, Traded Goods

\begin{tabular}{ccccccc}
\hline \hline & 1975 & 1985 & 1990 & 1995 & 2000 & $\begin{array}{c}\text { Total } \% \\
\text { Change }\end{array}$ \\
\hline (A) Unit Input & Usages & of & Imported & Intermediates $(I T / G O, \%)$ & \\
\hline China & -- & 1.5 & 1.7 & 2.8 & 3.3 & 120.5 \\
Indonesia & 3.2 & 3.1 & 3.2 & 3.8 & 4.1 & 29.8 \\
Japan & 2.0 & 2.2 & 1.9 & 2.0 & 2.4 & 19.6 \\
Korea & 8.5 & 7.8 & 7.3 & 7.6 & 8.7 & 2.3 \\
Malaysia & 4.2 & 9.1 & 10.0 & 16.0 & 24.7 & 486.1 \\
Taiwan & -- & 6.7 & 9.3 & 12.5 & 15.2 & 126.2 \\
Philippines & 4.0 & 4.6 & 6.4 & 8.0 & 16.0 & 303.1 \\
Singapore & 16.3 & 26.2 & 28.1 & 28.3 & 24.5 & 50.3 \\
Thailand & 3.1 & 5.1 & 10.9 & 12.0 & 13.7 & 339.3 \\
U.S. & 0.7 & 1.1 & 1.2 & 1.8 & 2.2 & 229.9 \\
\hline \hline (B) Input Share of Trade (IT/TT, \%) & & & & \\
\hline China & -- & 36.1 & 61.7 & 62.3 & 65.2 & 80.8 \\
Indonesia & 38.8 & 51.2 & 38.7 & 45.6 & 49.7 & 27.9 \\
Japan & 71.8 & 61.1 & 51.7 & 47.3 & 43.6 & -39.3 \\
Korea & 67.2 & 69.7 & 67.4 & 64.0 & 71.1 & 5.8 \\
Malaysia & 36.9 & 46.0 & 36.2 & 45.3 & 71.4 & 93.4 \\
Taiwan & -- & 69.1 & 64.6 & 63.1 & 63.3 & -8.5 \\
Philippines & 41.5 & 66.6 & 47.4 & 46.2 & 63.1 & 52.1 \\
Singapore & 54.2 & 62.4 & 53.8 & 59.7 & 61.8 & 14.1 \\
Thailand & 45.3 & 45.7 & 53.6 & 56.7 & 67.9 & 49.9 \\
U.S. & 43.3 & 29.8 & 24.7 & 31.2 & 33.9 & -21.6 \\
\hline \hline (C) Exported Inputs in Total Exports (\%) & & & \\
\hline China & -- & 64.9 & 52.1 & 44.6 & 36.7 & -43.4 \\
Indonesia & 86.9 & 94.1 & 81.6 & 70.3 & 71.3 & -18.0 \\
Japan & 53.5 & 36.8 & 42.5 & 51.1 & 55.0 & 2.8 \\
Korea & 47.2 & 41.6 & 39.8 & 61.6 & 64.7 & 37.0 \\
Malaysia & 69.6 & 86.7 & 73.4 & 63.0 & 62.1 & -10.8 \\
Taiwan & -- & 35.2 & 42.6 & 54.5 & 67.4 & 91.4 \\
Philippines & 83.6 & 64.0 & 48.7 & 55.6 & 66.0 & -21.0 \\
Singapore & 49.2 & 52.2 & 48.0 & 50.7 & 66.9 & 35.9 \\
Thailand & 74.2 & 62.9 & 43.1 & 49.1 & 55.4 & -25.4 \\
U.S. & 70.6 & 66.7 & 61.3 & 58.9 & 61.5 & -12.8 \\
\hline \hline
\end{tabular}


Table 2 Regression Results for Year 2000, no domestic flows

\begin{tabular}{|c|c|c|c|}
\hline & OLS & OLS & OLS \\
\hline & $\log M_{j i}^{g h}$ & $\log T_{j i}^{g}$ & $\log \left(\frac{M_{j i}^{g h}}{T_{j i}^{g}}\right)$ \\
\hline $\log \mu_{g}^{h} X_{i}^{h}$ & $\begin{array}{c}0.7109 * * * \\
(0.0152)\end{array}$ & & \\
\hline $\log E_{i}^{g}$ & & $\begin{array}{c}0.5495 * * * \\
(0.0305)\end{array}$ & \\
\hline $\log \left(\frac{\mu_{g}^{h} X_{i}^{h}}{E_{i}^{g}}\right)$ & & & $\begin{array}{c}0.9823 * * * \\
(0.0059)\end{array}$ \\
\hline $\log \left(\left|\Delta\left(\frac{K}{L}\right)\right|\right)$ & $\begin{array}{c}0.0033 \\
(0.0558)\end{array}$ & $\begin{array}{c}0.1625 * * * \\
(0.0560)\end{array}$ & $\begin{array}{c}-0.0756^{* * *} \\
(0.0275)\end{array}$ \\
\hline $\log \left(1+\operatorname{tar}_{j i}{ }^{g}\right)$ & $\begin{array}{c}0.0341 \\
(0.0485)\end{array}$ & $\begin{array}{l}-0.0486 \\
(0.0533)\end{array}$ & $\begin{array}{c}-0.0389 * \\
(0.0214)\end{array}$ \\
\hline $\log (D I S T)$ & $\begin{array}{c}-0.2533 * * * \\
(0.0782) \\
\end{array}$ & $\begin{array}{c}-0.2850 * * * \\
(0.0842) \\
\end{array}$ & $\begin{array}{l}0.0703 * \\
(0.0379) \\
\end{array}$ \\
\hline Contig & $\begin{array}{c}1.2136 * * * \\
(0.2392)\end{array}$ & $\begin{array}{c}1.2014 * * * \\
(0.2640)\end{array}$ & $\begin{array}{c}0.1521 * * \\
(0.0703)\end{array}$ \\
\hline Lang & $\begin{array}{c}0.4829 * * * \\
(0.1583)\end{array}$ & $\begin{array}{c}0.3113 * * \\
(0.1407)\end{array}$ & $\begin{array}{c}0.1483 * * \\
(0.0695)\end{array}$ \\
\hline $\log \left(G O_{j}^{g}\right)$ & $\begin{array}{c}0.5480 * * * \\
(0.0320) \\
\end{array}$ & $\begin{array}{c}0.7152 * * * \\
(0.0289)\end{array}$ & $\begin{array}{c}-0.0434 * * * \\
(0.0114)\end{array}$ \\
\hline Constant & $\begin{array}{c}-10.0221 * * * \\
(0.8597)\end{array}$ & $\begin{array}{c}-8.7749 * * * \\
(0.8720)\end{array}$ & $\begin{array}{l}-0.0996 \\
(0.3565)\end{array}$ \\
\hline R-squared & 0.5545 & 0.4721 & 0.7256 \\
\hline $\mathrm{N}$ & 45436 & 80614 & 45436 \\
\hline
\end{tabular}

*Standard errors clustered at country-pair level are in parenthesis. 
Table 3 Input Shares of Bilateral Trade and Industrial Absorption Shares, Correlations

\begin{tabular}{cccccc}
\hline \hline & 1975 & 1985 & 1990 & 1995 & 2000 \\
\hline China & -- & 0.54 & 0.45 & 0.46 & 0.56 \\
Indonesia & 0.71 & 0.52 & 0.55 & 0.70 & 0.62 \\
Japan & 0.54 & 0.51 & 0.57 & 0.63 & 0.63 \\
Korea & 0.47 & 0.37 & 0.41 & 0.53 & 0.64 \\
Malaysia & 0.54 & 0.40 & 0.54 & 0.47 & 0.61 \\
Philippines & 0.50 & 0.66 & 0.65 & 0.69 & 0.74 \\
Singapore & 0.63 & 0.62 & 0.65 & 0.71 & 0.66 \\
Thailand & 0.41 & 0.47 & 0.51 & 0.62 & 0.63 \\
Taiwan & -- & 0.44 & 0.48 & 0.58 & 0.66 \\
USA & 0.42 & 0.59 & 0.60 & 0.61 & 0.64 \\
\hline \hline
\end{tabular}

Table 4 Baseline Regression Results, Full Sample

\begin{tabular}{|c|c|c|c|c|c|c|}
\hline OLS & $\begin{array}{c}\text { Pooled } \\
\log \left(\frac{M_{j i}^{g h}}{T_{j i}^{g}}\right)\end{array}$ & $\begin{array}{c}1975 \\
\log \left(\frac{M_{j i}^{g h}}{T_{j i}^{g}}\right)\end{array}$ & $\log \left(\frac{M_{j i}^{g h}}{T_{j i}^{g}}\right)$ & $\begin{array}{c}1990 \\
\log \left(\frac{M_{j i}^{g h}}{T_{j i}^{g}}\right)\end{array}$ & $\log \left(\frac{M_{j i}^{g h}}{T_{j i}^{g}}\right)$ & $\begin{array}{c}2000 \\
\log \left(\frac{M_{j i}^{g h}}{T_{j i}^{g}}\right)\end{array}$ \\
\hline $\log \left(\frac{\mu_{g}^{h} X_{i}^{h}}{E_{i}^{g}}\right)$ & $\begin{array}{c}0.9391 * * * \\
(0.0058)\end{array}$ & $\begin{array}{c}0.9183 * * * \\
(0.0110)\end{array}$ & $\begin{array}{c}0.8993 * * * \\
(0.0099)\end{array}$ & $\begin{array}{c}0.9210 * * * \\
(0.0091)\end{array}$ & $\begin{array}{c}0.9407 * * * \\
(0.0094)\end{array}$ & $\begin{array}{c}0.9764 * * * \\
(0.0066)\end{array}$ \\
\hline Constant & $\begin{array}{c}-0.6713 * * * \\
(0.0334)\end{array}$ & $\begin{array}{c}-0.4333 * * * \\
(0.0523)\end{array}$ & $\begin{array}{c}-0.7533 * * * \\
(0.0493)\end{array}$ & $\begin{array}{c}-0.8568 * * * \\
(0.0517)\end{array}$ & $\begin{array}{c}-0.7930 * * * * \\
(0.0470)\end{array}$ & $\begin{array}{c}-0.5116^{* * * *} \\
(0.0366)\end{array}$ \\
\hline $\begin{array}{l}\text { R-Squared } \\
\mathrm{N}\end{array}$ & $\begin{array}{l}0.7042 \\
195311\end{array}$ & $\begin{array}{c}0.7880 \\
21505\end{array}$ & $\begin{array}{l}0.6636 \\
36278\end{array}$ & $\begin{array}{c}0.6541 \\
39459\end{array}$ & $\begin{array}{c}0.6781 \\
45360\end{array}$ & $\begin{array}{c}0.7655 \\
52709\end{array}$ \\
\hline
\end{tabular}

*Standard errors clustered at country-pair level are in parenthesis. Tests on the slope being equal to 1 are rejected in all regressions with a $\mathrm{p}$-value of 0.000 .

Table 5 Frequencies of Unpredicted Zeros

$1975 \quad 1985 \quad 1990 \quad 1995 \quad 2000$

$\%$ of Sample with $\frac{\sum_{h} \mu_{g}^{h} X_{i}^{h}}{E_{i}^{g}}>0 \quad \& \frac{M_{j i}^{g}}{T_{j i}^{g}}=0 \quad 22 \% \quad 17 \% \quad 15 \% \quad 12 \% \quad 11 \%$

$\%$ of Sample with $\frac{\mu_{g}^{h} X_{i}^{h}}{E_{i}^{g}}>0 \quad \& \frac{M_{j i}^{g h}}{T_{j i}^{g}}=0 \quad 40 \% \quad 44 \% \quad 43 \% \quad 38 \% \quad 28 \%$


Table 6 Regression Results with bilateral controls

\begin{tabular}{|c|c|c|c|c|c|c|}
\hline OLS & Pooled & 1975 & 1985 & 1990 & 1995 & 2000 \\
\hline & $\log \left(\frac{M_{j i}^{g h}}{T_{j i}^{g}}\right)$ & $\log \left(\frac{M_{j i}^{g h}}{T_{j i}^{g}}\right)$ & $\log \left(\frac{M_{j i}^{g h}}{T_{j i}^{g}}\right)$ & $\log \left(\frac{M_{j i}^{g h}}{T_{j i}^{g}}\right)$ & $\log \left(\frac{M_{j i}^{g h}}{T_{j i}^{g}}\right)$ & $\log \left(\frac{M_{j i}^{g h}}{T_{j i}^{g}}\right)$ \\
\hline $\log \left(\frac{\mu_{g} \boldsymbol{X}_{i}}{E_{i}^{g}}\right)$ & $\begin{array}{c}0.9517 * * * \\
(0.0059)\end{array}$ & $\begin{array}{c}0.9150 * * * \\
(0.0117)\end{array}$ & $\begin{array}{c}0.9072 * * * \\
(0.0115)\end{array}$ & $\begin{array}{c}0.9453 * * * \\
(0.0084)\end{array}$ & $\begin{array}{c}0.9550 * * * \\
(0.0092)\end{array}$ & $\begin{array}{c}0.9852 * * * \\
(0.0057)\end{array}$ \\
\hline $\log (D I S T)$ & $\begin{array}{c}0.0229 \\
(0.0230)\end{array}$ & $\begin{array}{l}-0.0016 \\
(0.0281)\end{array}$ & $\begin{array}{c}0.0080 \\
(0.0320)\end{array}$ & $\begin{array}{c}0.0214 \\
(0.0340)\end{array}$ & $\begin{array}{c}0.0376 \\
(0.0334)\end{array}$ & $\begin{array}{c}0.0085 \\
(0.0279)\end{array}$ \\
\hline Contig & $\begin{array}{c}0.2152 * * * \\
(0.0647)\end{array}$ & $\begin{array}{c}0.1470 \\
(0.1097)\end{array}$ & $\begin{array}{c}0.1253 \\
(0.1115)\end{array}$ & $\begin{array}{c}0.2171 * * \\
(0.1082)\end{array}$ & $\begin{array}{c}0.2924 * * * \\
(0.0992)\end{array}$ & $\begin{array}{c}0.1136 \\
(0.0780)\end{array}$ \\
\hline Lang & $\begin{array}{c}0.1735 * * * \\
(0.0491)\end{array}$ & $\begin{array}{l}-0.0204 \\
(0.1059)\end{array}$ & $\begin{array}{l}0.1490 * \\
(0.0794)\end{array}$ & $\begin{array}{l}0.1854 * \\
(0.0941)\end{array}$ & $\begin{array}{c}0.2382 * * * \\
(0.0629)\end{array}$ & $\begin{array}{c}0.2181 * * * \\
(0.0572)\end{array}$ \\
\hline HOME & $\begin{array}{c}0.5583 * * * \\
(0.0745)\end{array}$ & $\begin{array}{l}-0.0629 \\
(0.0967)\end{array}$ & $\begin{array}{c}0.2678 * * \\
(0.1065)\end{array}$ & $\begin{array}{c}0.7353 * * * \\
(0.0991)\end{array}$ & $\begin{array}{c}0.7789 * * * \\
(0.0940)\end{array}$ & $\begin{array}{c}0.5868 * * * \\
(0.1022)\end{array}$ \\
\hline Constant & $\begin{array}{c}-0.9247 * * * \\
(0.1947)\end{array}$ & $\begin{array}{c}-0.4323 * \\
(0.2336)\end{array}$ & $\begin{array}{c}-0.8598 * * * \\
(0.2694)\end{array}$ & $\begin{array}{c}-1.0839 * * * \\
(0.2836)\end{array}$ & $\begin{array}{c}-1.1960 * * * \\
(0.2831)\end{array}$ & $\begin{array}{c}-0.6607 * * * \\
(0.2434)\end{array}$ \\
\hline R-squared & 0.7096 & 0.7884 & 0.6654 & 0.6641 & 0.6869 & 0.7712 \\
\hline $\mathrm{N}$ & 195311 & 21505 & 36278 & 39459 & 45360 & 52709 \\
\hline
\end{tabular}

*Standard errors clustered at country-pair level are in parenthesis. Tests on the slope being equal to 1 are rejected in all regressions with a p-value of 0.000 . 
Table 7 Regression Results with bilateral controls, no domestic flows

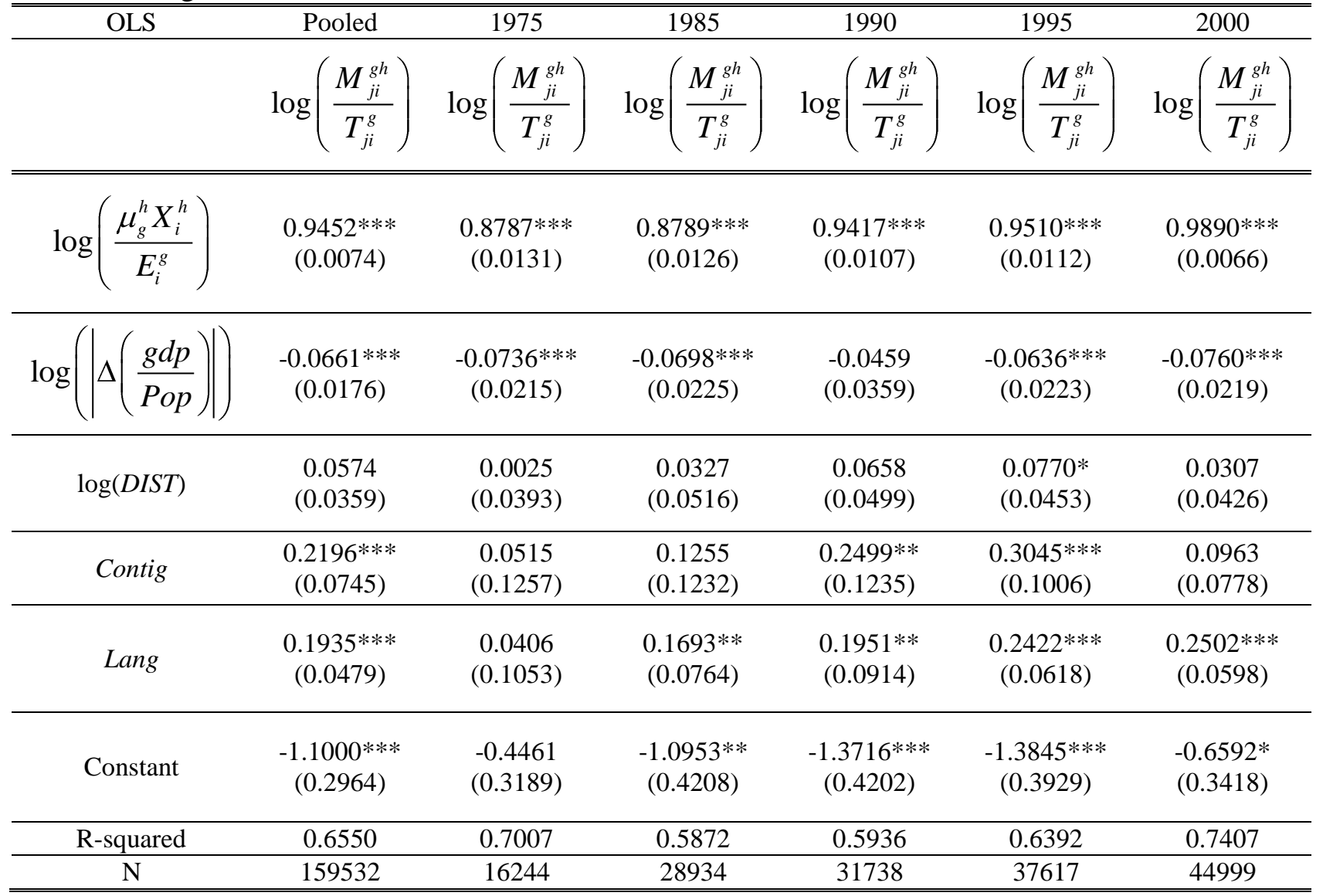

*Standard errors clustered at country-pair level are in parenthesis. Tests on the slope being equal to 1 are rejected in all regressions with a p-value of 0.000 , except for the year 2000 which is characterized by a p-value of 0.1008 . 
Table 8 Growth Regressions Results with bilateral controls

\begin{tabular}{|c|c|c|c|c|c|}
\hline OLS & Pooled & $1975-85$ & $1985-90$ & 1990-95 & $1995-2000$ \\
\hline & $\Delta \log \left(\frac{M_{j i}^{g h}}{T_{j i}^{g}}\right)$ & $\Delta \log \left(\frac{M_{j i}^{g h}}{T_{j i}^{g}}\right)$ & $\Delta \log \left(\frac{M_{j i}^{g h}}{T_{j i}^{g}}\right)$ & $\Delta \log \left(\frac{M_{j i}^{g h}}{T_{j i}^{g}}\right)$ & $\Delta \log \left(\frac{M_{j i}^{g h}}{T_{j i}^{g}}\right)$ \\
\hline$\Delta \log \left(\frac{\mu_{g}^{h} X_{i}^{\prime}}{E_{i}^{g}}\right.$ & $\begin{array}{c}0.8594 * * * \\
(0.0129)\end{array}$ & $\begin{array}{c}0.9118 * * * \\
(0.0131)\end{array}$ & $\begin{array}{c}0.8623 * * * \\
(0.0164)\end{array}$ & $\begin{array}{c}0.7309 * * * \\
(0.0274)\end{array}$ & $\begin{array}{c}0.8521 * * * \\
(0.0187)\end{array}$ \\
\hline $\log (D I S T)$ & $\begin{array}{l}-0.0162 \\
(0.0111)\end{array}$ & $\begin{array}{l}-0.0024 \\
(0.0239)\end{array}$ & $\begin{array}{l}-0.0154 \\
(0.0287)\end{array}$ & $\begin{array}{l}0.0204 * \\
(0.0116)\end{array}$ & $\begin{array}{l}-0.0455 \\
(0.0330)\end{array}$ \\
\hline Contig & $\begin{array}{c}-0.1007 * * * \\
(0.0315)\end{array}$ & $\begin{array}{l}-0.0320 \\
(0.1369)\end{array}$ & $\begin{array}{l}-0.0806 \\
(0.0851)\end{array}$ & $\begin{array}{l}0.0824 * \\
(0.0418)\end{array}$ & $\begin{array}{c}-0.2265 * * \\
(0.0863)\end{array}$ \\
\hline Lang & $\begin{array}{c}0.0195 \\
(0.0296)\end{array}$ & $\begin{array}{c}0.2572 \\
(0.1706)\end{array}$ & $\begin{array}{l}-0.0380 \\
(0.0712)\end{array}$ & $\begin{array}{c}-0.0621 * * \\
(0.0275)\end{array}$ & $\begin{array}{c}0.0414 \\
(0.0737)\end{array}$ \\
\hline HOME & $\begin{array}{l}-0.0202 \\
(0.0387)\end{array}$ & $\begin{array}{c}0.3107 * * * \\
(0.1015)\end{array}$ & $\begin{array}{l}0.1885^{*} \\
(0.1000)\end{array}$ & $\begin{array}{c}0.0025 \\
(0.0426)\end{array}$ & $\begin{array}{c}-0.2824 * * * \\
(0.1041)\end{array}$ \\
\hline Constant & $\begin{array}{c}0.1133 \\
(0.0972)\end{array}$ & $\begin{array}{l}-0.3181 \\
(0.2187)\end{array}$ & $\begin{array}{l}-0.0270 \\
(0.2519)\end{array}$ & $\begin{array}{l}-0.1500 \\
(0.0999)\end{array}$ & $\begin{array}{l}0.5233 * \\
(0.2822)\end{array}$ \\
\hline R-squared & 0.3218 & 0.5328 & 0.2935 & 0.1580 & 0.3142 \\
\hline $\mathrm{N}$ & 125524 & 16438 & 30519 & 36894 & 41673 \\
\hline
\end{tabular}

*Standard errors clustered at country-pair level are in parenthesis. Tests on the slope being equal to 1 are rejected in all regressions with a p-value of 0.000 . 